\title{
Market-level exposure to state antismoking media campaigns and public support for tobacco control policy in the United States, 2001-2002
}

\author{
Jeff Niederdeppe, ${ }^{1}$ Maxwell Kellogg, ${ }^{2}$ Christofer Skurka, ${ }^{1}$ Rosemary J Avery ${ }^{2}$
}

\begin{abstract}
${ }^{1}$ Department of Communication, Cornell University, Ithaca, New York, USA

${ }^{2}$ Department of Policy Analysis and Management, Cornell University, Ithaca, New York, USA
\end{abstract}

\section{Correspondence to} Dr Jeff Niederdeppe, Department of Communication, Cornell University, 476 Mann

Library Building, Ithaca, NY 14853, USA; jdn56@cornell.edu

Received 31 October 2016 Revised 6 February 2017 Accepted 14 February 2017 Published Online First 18 March 2017
ABSTRACT

Objective This study tests whether exposure to state antismoking media campaigns is associated with increased support for comprehensive bans on smoking indoors and cigarette advertising.

Methods We combine commercially available data on market-level state-sponsored antismoking advertisements with three waves of the Current Population Survey's Tobacco Use Supplement to test the relationship between market-level volume of state antismoking advertising exposure and support for tobacco control policy between 2001 and 2002. We use logistic regression to assess which message themes employed in the advertisements are associated with increased support for tobacco control policy.

Results The overall market-level volume of exposure to state antismoking ads targeted to adults or the general population was associated with significant increases in support for comprehensive indoor smoking bans. These effects were driven by exposure to ads emphasising the health consequences of smoking to others, anti-industry appeals and irrationality/addiction appeals. Evidence of campaign impact on support for tobacco advertising bans was less clear and, when statistically significant, small in magnitude relative to the impact of the state economic and tobacco control policy environment. Conclusions This study shows that that large-scale antismoking media campaigns can have a meaningful secondary impact on support for comprehensive indoor smoking bans. Future research should identify the conditions under which mass media campaigns primarily targeting smoking behaviour may influence public support for a variety of other tobacco control policies.

\section{INTRODUCTION}

Many scholars suggest that large-scale, mass media antismoking campaigns have the potential to increase public willingness to support tobacco control policy. ${ }^{1-3}$ While the policymaking process is shaped by more inputs than public opinion alone, public policy support can influence how policy makers weigh the relative importance of issues and increase the likelihood of policy change. ${ }^{4}$ This is particularly true in states where citizens vote directly on policy proposals. Anecdotally, many states (eg, California and New York) have passed extensive tobacco control policies (clean indoor air laws, higher cigarette excise taxes, stronger restrictions to youth access) concurrent with, or in the wake of, extensive mass media campaigns promoting smoking cessation. Despite these observations, research has yet to parse out the specific impact of antismoking media campaigns in shaping public support for tobacco control policy.

There are good reasons to predict that large-scale antismoking media campaigns could have valuable secondary impacts on support for tobacco control policy, which in turn may influence policy adoption. Studies from across the globe show that campaigns promoting indoor smoking bans increases support for these policies. ${ }^{5-12}$ In turn, there is strong evidence that comprehensive smoking bans reduce exposure to secondhand smoke (SHS) and related health problems, ${ }^{11-13}$ decrease smoking rates ${ }^{13} 14$ and increase support for these policies. ${ }^{14-17}$

Most US state laws prohibit state antismoking media campaigns from explicit advocacy of state or local policies. However, messages which target tobacco use itself, but make no mention of policy, could have broader impacts on denormalisng tobacco, making tobacco promotion and use seem publicly unacceptable and thus making policies to denormalise them seem more acceptable. ${ }^{18} 19$ The limited available evidence is consistent with this assertion.

For instance, many state-sponsored smoking cessation media campaigns feature messages emphasising potential harms of smoking to others, ${ }^{20}$ and knowledge of the harms associated with SHS predicts favourable attitudes towards restrictions on smoking in public. ${ }^{21}$ These patterns suggest that state antismoking campaigns featuring messages about the harms of smoking to others (via SHS) may increase support for indoor smoking bans.

There also is evidence suggesting that messages which emphasise negative behaviours of the tobacco industry (anti-industry themes), another theme employed in state campaigns, ${ }^{20}$ may have important secondary effects on support for tobacco control policy. If state antismoking media campaigns using anti-industry themes do influence perceptions about the deceptive tactics employed by the tobacco industry, these beliefs may lead people to support policies that denormalise tobacco use and its promotion. Indeed, the more often smokers report being exposed to antismoking ads, the stronger their industry denormalisation beliefs, ${ }^{22}$ and belief that the tobacco industry has become denormalised predicts support for tobacco control policy. ${ }^{8}$ A recent study also found that New York state residents reporting exposure to state antismoking messages about the negative effects of point-of-sale cigarette ads were more likely than those unexposed to support banning tobacco product displays in stores. ${ }^{23}$ Combined, these studies suggest that exposure to antismoking ads about the tobacco 
industry's marketing tactics or actions could increase support for both comprehensive indoor smoking bans (denormalising tobacco use) and comprehensive bans on tobacco ads (denormalising the industry itself).

\section{Study objectives}

Previous studies have linked small-scale, targeted media campaigns using specific message themes to increased public support for closely related tobacco control policies. ${ }^{5-1023}$ Using a large national sample, this study tests whether exposure to state antismoking media campaigns employing a variety of different message themes is associated with increased support for comprehensive indoor smoking bans (including workplaces, restaurants and bars) and comprehensive tobacco advertising bans (including print, point-of-sale and Internet ads). We combine commercially available data on market-level, state-sponsored antismoking ads with three waves of the Current Population Survey's Tobacco Use Supplement (CPS-TUS) to test the relationship between market-level volume of state antismoking ad exposure and support for tobacco control policy in 2001 and 2002, controlling for demographic factors and other state and national antismoking campaigns, programmes and policies.

\section{METHODS}

\section{Market-level antismoking ad exposure}

We obtained data on airings of state-sponsored antismoking ads from Kantar/TNS Media Intelligence. These data include information on the time, date, channel and designated market area (DMA) of all 218721 airings of ads between 1998 and 2004 in the USA. In addition, these data include 404589 airings corresponding to the national 'truth' campaign targeted primarily to youth ages $12-17 .^{24}$ We used content analysis to identify the thematic content of all state-sponsored antismoking ads (described in detail elsewhere). ${ }^{20}$ We trained two coders to identify each ad's target audience (youth or adult/general targeted) using video recordings of each of the 1320 unique ads; a team of six coders then identified specific message themes featured in each ad, permitting each ad to feature multiple themes. This process was reliable (see table 1 for definitions, examples and intercoder reliability statistics). We focus on five themes that appeared regularly in adult/general-targeted state antismoking ads: messages about health consequences to self, health consequences to others, anti-industry appeals, irrationality/addiction appeals and efficacy appeals. ${ }^{20}$ We use data on the overall volume of youth-targeted state antismoking ads and truth campaign ads as additional variables in our analyses.

\section{CPS TUS survey data}

We matched data on market-level (DMA) ad airings to individual-level survey data from the June 2001, November 2001 and February 2002 samples of the CPS-TUS. These CPS-TUS monthly samples overlapped with the timing of our market-level ad data and contain survey questions on support for tobacco control policies. The CPS identifies respondents by state of residence, county and metropolitan statistical area (MSA), although MSA data are withheld for respondents in sparsely sampled locations. All US counties are contained entirely within a single DMA, so we matched respondents with county information to their corresponding DMA. For respondents with missing county data, we matched respondents with available MSA information if the remainder of their MSA was entirely contained within a single DMA. We were unable to DMA match those respondents who were missing both county and MSA data. Of the 330620 respondents in the three CPS waves, we matched $38.1 \%$ to a DMA by county and another $23.1 \%$ by MSA, producing a total match rate of $61.2 \%$. Of these respondents, $113171(63.0 \%)$ completed the TUS and 102831 of those respondents (90.9\%) responded to all of the questions considered in our analyses.

\section{Measures}

Independent variable: ad exposure

We measured market-level antismoking ad exposure for the resulting sample of 102831 adult respondents with a known DMA over the age of 18 who completed the CPS-TUS by summing the volume of ads appearing before the first day of the fielding period of a respondent's sample (1 June or 1 November of 2001 or 1 February of 2002). We calculated separate ad exposure measures for state-sponsored adult/general-targeted ads (overall and by message theme), state-sponsored youth-targeted ads and truth campaign ads. We calculated raw sums of the airings in the $3,6,9,12,18,24$ or 36 -month window ending on that day and a weighted sum of all available airings prior to that day where the weight began with a value of 1 and decayed exponentially in time elapsed between the ad airing and the beginning of the fielding period. For this weight, we calculated half lives (the point at which we estimate exposure from a previous time-period to retain half of its impact) of 1, 2, 3 or 6 months. We chose to calculate weighted, half-life measures to capture the

Table 1 State antismoking advertisement themes and intercoder reliability

\begin{tabular}{|c|c|c|c|}
\hline Theme & Definition & Example phrase or tagline & $\begin{array}{l}\text { Cohen's } \\
\text { к }\end{array}$ \\
\hline $\begin{array}{l}\text { Youth argeted (vs adult or } \\
\text { general targeted) }\end{array}$ & Themes aimed to deter youth from initiating smoking & $\begin{array}{l}\text { 'Smelly puking habit;' } \\
\text { 'truth' (Florida state campaign) }\end{array}$ & 0.99 \\
\hline Efficacy appeal & $\begin{array}{l}\text { Themes with a focus on quitting tobacco; these often include a quit help line or } \\
\text { website }\end{array}$ & 'You can do it!' & 0.92 \\
\hline $\begin{array}{l}\text { Health consequences } \\
\text { to self }\end{array}$ & $\begin{array}{l}\text { Themes that raise awareness of the health consequences of smoking or benefits of } \\
\text { quitting }\end{array}$ & $\begin{array}{l}\text { 'Smoking shortens your life;' 'If smoking did on the } \\
\text { outside what it did on the inside, nobody would } \\
\text { smoke.' }\end{array}$ & 0.94 \\
\hline Anti-industry appeal & $\begin{array}{l}\text { Themes claiming that tobacco companies know that their product kills and is } \\
\text { addictive, manipulate their customers and only care about company profits }\end{array}$ & $\begin{array}{l}\text { 'Cigarettes kill, that's the goal of Big Tobacco;' 'It's } \\
\text { time to break the tobacco industry's grip.' }\end{array}$ & 0.96 \\
\hline $\begin{array}{l}\text { Health consequences to } \\
\text { others }\end{array}$ & Themes that focus on the impact of secondhand smoke & 'Someone smoking around us means we all do.' & 0.90 \\
\hline $\begin{array}{l}\text { Irrationality/addiction } \\
\text { appeals }\end{array}$ & $\begin{array}{l}\text { Themes that attempt to debunk the myth that cigarettes are good for mental health/ } \\
\text { stability or describe the addictiveness of cigarettes or nicotine }\end{array}$ & $\begin{array}{l}\text { 'Cigarettes only add to your stress;' 'Cigarettes are } \\
\text { addictive.' }\end{array}$ & 0.97 \\
\hline
\end{tabular}

GED, General Education Diploma; $\kappa$, kappa. For additional details on coding categories, see Niederdeppe et al. ${ }^{20}$ 
reality that the impact of exposure to an antismoking message is likely to decay over time. Creating weighted measures provided an efficient way to account for this tendency without having to include separate measures for multiple lags. ${ }^{25}$ Model results were generally consistent across half-life measures; we report results from the exponential decay approach with a 2-month half-life, as this measure offered the most precise coefficient estimates measured by the size of SEs and is consistent with other studies using a similar time frame. ${ }^{26}$ Table 2 shows the volume of exposure to each type of ad.

\section{Dependent variables: policy support}

We gauged support for two types of tobacco control policies measured in the 2001-2002 CPS-TUS: comprehensive (1) indoor smoking bans and (2) tobacco advertising bans. The CPS-TUS asked respondents whether they believe that smoking should be allowed in 'all areas,' 'some areas' or 'not at all' within: hospitals, indoor work areas, bars and cocktail lounges, indoor sporting events and/or indoor shopping malls. We aggregated responses to these items into a single binary variable (support for comprehensive indoor smoking bans), indicating whether or not a respondent believed that smoking should be banned in 'all areas' for all six location types (30.8\% supported a comprehensive ban). The surveys also asked whether respondents believe that advertising of tobacco products should be allowed 'always,' 'under some conditions'or 'not at all.' We created a binary variable (support for comprehensive tobacco advertising bans) indicating whether or not a respondent believed that tobacco advertising should be allowed 'not at all' (48.2\% ; table 2$)$.

\section{Control variables}

All models controlled for demographics (from table 2) and statelevel policy and economic factors with measures taken from publicly available data. ${ }^{27}$ We controlled for the per cent of state gross domestic product (GDP) attributed to tobacco farming, state excise taxes per cigarette pack, per capita tobacco control funding, number of location-specific smoking bans (public schools, private schools, public transit, restaurants, recreational facilities, health facilities, childcare facilities and/or private work sites) and total Alciati score (a measure of legal control over youth tobacco access) ${ }^{28}$ in the respondent's state-year of survey.

\section{Analytic approach}

We estimated logistic regression models to predict support for each policy. We regressed each policy support measure on a series of individual-level demographic controls from CPS data, statelevel policy and economic characteristics and various combinations of market-level ad exposure measures (described in detail below). We ran several models for each outcome because theme-specific ad exposure measures were highly correlated with one another (table 3). The first model focused on the coefficient for the total volume of adult/general-targeted ads (Model 1). The second set of models included the volume of each adult/ general-targeted ad theme in separate models (but including all of the aforementioned controls; Model 2). Models 3 through 6 include various combinations of ad themes, with Model 3 including all ad themes and Models 4 through 6 sequentially dropping variables with the highest variance inflation factors (VIFs) from Model 3 to assess the impact of high multicollinearity on the stability of model coefficients.
Table 2 Descriptive statistics on variables involved in the analysis $(n=102831)$

\begin{tabular}{|c|c|c|}
\hline & Mean & SD \\
\hline \multicolumn{3}{|l|}{ Independent variables } \\
\hline $\begin{array}{l}\text { Volume of exposure* to truth antismoking ads_-overall } \\
\text { (in 100s) }\end{array}$ & 9.75 & 6.23 \\
\hline $\begin{array}{l}\text { Volume of exposure to state antismoking ads_-overall } \\
\text { (in 100s) }\end{array}$ & 1.29 & 2.16 \\
\hline $\begin{array}{l}\text { Volume of exposure to state antismoking ads_-general/ } \\
\text { adult targeted (in 100s) }\end{array}$ & 1.03 & 1.83 \\
\hline $\begin{array}{l}\text { Volume of exposure to state antismoking ads- } \\
\text { youth targeted (in 100s) }\end{array}$ & 0.26 & 0.65 \\
\hline \multicolumn{3}{|l|}{$\begin{array}{l}\text { Volume of exposure to state antismoking ads—specific } \\
\text { general/adult-targeted ad themes (in 100s) }\end{array}$} \\
\hline Efficacy appeal & 0.69 & 1.24 \\
\hline Health consequences to others & 0.43 & 0.95 \\
\hline Health consequences to self & 0.43 & 0.85 \\
\hline Anti-industry appeal & 0.31 & 0.83 \\
\hline Irrationality/ addiction appeal & 0.25 & 0.54 \\
\hline \multicolumn{3}{|l|}{ State-level policy variables } \\
\hline $\begin{array}{l}\% \text { of state GDP in a year generated from tobacco } \\
\text { farming }\end{array}$ & 0.02 & 0.06 \\
\hline $\begin{array}{l}\text { Excise tax (in \$) per cigarette pack, excluding federal } \\
\text { excise taxes, adjusted for inflation }\end{array}$ & 0.50 & 0.32 \\
\hline $\begin{array}{l}\text { Extensiveness of laws restricting youth access to } \\
\text { tobacco } \\
\text { (total Alciati score) } \dagger\end{array}$ & 16.70 & 6.54 \\
\hline $\begin{array}{l}\text { Per capita tobacco control funding (in dollars), } \\
\text { adjusted for inflation }\end{array}$ & 3.38 & 2.48 \\
\hline $\begin{array}{l}\text { Number of location bans on cigarette use (range } \\
0-9) \ddagger\end{array}$ & 0.69 & 0.97 \\
\hline Dependent variables & Percentage & n \\
\hline Support for comprehensive indoor smoking bans & 30.8 & 31720 \\
\hline Support for comprehensive tobacco advertising bans & 48.2 & 49551 \\
\hline Demographic control variables & Percentage & $\mathbf{n}$ \\
\hline \multicolumn{3}{|l|}{ Age } \\
\hline $18-24$ & 9.6 & 9901 \\
\hline $25-34$ & 19.3 & 19887 \\
\hline $35-44$ & 22.1 & 22759 \\
\hline $45-54$ & 19.4 & 19921 \\
\hline $55-64$ & 12.7 & 13069 \\
\hline $65-74$ & 9.3 & 9546 \\
\hline 75 or older & 7.5 & 7748 \\
\hline Female (vs male) & 55.8 & 57380 \\
\hline \multicolumn{3}{|l|}{ Race } \\
\hline White & 83.4 & 85812 \\
\hline Black & 11.3 & 11663 \\
\hline American-Indian, Aleut, Eskimo & 0.9 & 883 \\
\hline Asian or Pacific Islander & 4.3 & 4473 \\
\hline Hispanic/Latino ethnicity (vs not) & 9.75 & 10029 \\
\hline \multicolumn{3}{|l|}{ Educational attainment } \\
\hline Less than high school & 11.9 & 12232 \\
\hline GED (General Education Diploma) & 1.6 & 1,609 \\
\hline High school graduate & 29.5 & 30354 \\
\hline Some college & 28 & 28814 \\
\hline College graduate & 19.2 & 19740 \\
\hline At least some graduate school & 9.8 & 10082 \\
\hline Demographic control variables & Percentage & $n$ \\
\hline \multicolumn{3}{|l|}{ Annual household income (in \$) } \\
\hline Less than 5000 & 2.1 & 2126 \\
\hline
\end{tabular}




\section{Table 2 Continued}

\begin{tabular}{|c|c|c|}
\hline & Mean & SD \\
\hline $5000-7499$ & 2 & 2017 \\
\hline 7500-9999 & 2.1 & 2161 \\
\hline $10000-12499$ & 2.9 & 2941 \\
\hline $12500-14999$ & 2.6 & 2682 \\
\hline 15000-19999 & 4.4 & 4574 \\
\hline 20000-24999 & 5.8 & 5982 \\
\hline $25000-29999$ & 5.9 & 6046 \\
\hline $30000-34999$ & 5.6 & 5778 \\
\hline $35000-39999$ & 5.6 & 5723 \\
\hline $40000-49999$ & 8.7 & 8992 \\
\hline $50000-59999$ & 8.8 & 9020 \\
\hline $60000-74999$ & 9.7 & 9993 \\
\hline 75000 or more & 23.7 & 24411 \\
\hline Do not know & 1.9 & 1991 \\
\hline No response & 8.2 & 8394 \\
\hline \multicolumn{3}{|l|}{ Marital status } \\
\hline Married & 57.0 & 58620 \\
\hline Widowed & 7.2 & 7400 \\
\hline Divorced or separated & 14.2 & 14539 \\
\hline Never married & 21.7 & 22272 \\
\hline Demographic control variables & Percentage & n \\
\hline \multicolumn{3}{|l|}{ Employment status } \\
\hline Employed & 65.6 & 67478 \\
\hline Unemployed & 3.5 & 3618 \\
\hline Retired & 17.2 & 17688 \\
\hline Disabled & 3.6 & 3710 \\
\hline Not in labour force (other) & 10.1 & 10337 \\
\hline \multicolumn{3}{|l|}{ Citizenship status } \\
\hline Native citizen & 87.5 & 89983 \\
\hline Naturalised citizen & 5.4 & 5513 \\
\hline Not citizen & 7.1 & 7335 \\
\hline \multicolumn{3}{|l|}{ Student status } \\
\hline Not a student & 96.8 & 99585 \\
\hline Fulltime or part-time student & 3.1 & 3246 \\
\hline Has child in household $0-2$ years of age & 20.9 & 21535 \\
\hline Has child in household $3-5$ years of age & 21.5 & 22145 \\
\hline Has child in household 6-13 years of age & 41.5 & 42709 \\
\hline Has child in household $14-17$ years of age & 25.7 & 26436 \\
\hline Current smoker & 19.7 & 20246 \\
\hline Current smoker who has ever quit for more than 1 day & 14.3 & 14751 \\
\hline $\begin{array}{l}\text { Current smoker who quit for more than } 1 \text { day in past } \\
\text { year }\end{array}$ & 7.5 & 7710 \\
\hline
\end{tabular}

${ }^{*}$ Volume of exposure refers to a weighted sum of all available airings in a respondents' media market prior to the beginning of a CPS-TUS fielding period, where the weight began with a value of 1 and decayed exponentially with a 2-month half-life.

tSee Alciati et al. ${ }^{28}$

¥The locations included in the index are public schools, private schools, public transit, restaurants, recreational facilities, health facilities, childcare facilities and/or private work sites.

CPS-TUS, Current Population Survey's Tobacco Use Supplement; GDP, gross domestic product.

\section{RESULTS}

\section{Logistic regression models predicting support for comprehensive indoor smoking bans}

Model 1 in table 4 shows that market-level volume of exposure to adult/general-state antismoking ads predicts higher support for comprehensive indoor smoking bans $(B=0.10, p<0.001)$.
Greater excise taxes on cigarettes $(B=0.10, \mathrm{p}<0.01)$ and more laws restricting youth tobacco access $(B=0.01, p<0.01)$ also predict increased support for this policy. Market-level volume of youth-targeted ads, percentage of state GDP generated from tobacco farming, per capita tobacco control funding and the number of location bans on smoking already in place in a state were not associated with support. Results for each of these policy and economic variables were consistent across all models so we do not repeat them in the tables.

Model 2 shows that all five message themes predict increased support for indoor smoking bans, although these (separate) models did not consider the high correlations between each message theme (because single ads could contain multiple themes and many states aired a variety of ads reflecting different theme combinations). Models 3 through 6 reveal that the positive associations in Model 2 between both efficacy appeals and health consequences to self and support for indoor smoking bans appeared to be spurious, driven by high associations with other themes (leading to coefficients that switch signs when controlling for other ad themes and reflected in high VIFs for these variables). Model 5 appears to be the most parsimonious model without high multicollinearity, revealing that marketlevel volume of exposure to adult/general ads on health consequences to others $(B=0.11, p<0.001)$, anti-industry appeals $(B=0.09, p<0.001)$ and irrationality/addiction appeals $(B=0.08$, $\mathrm{p}<0.001)$ are independent and positive predictors of increased support for comprehensive indoor smoking bans.

To better understand the magnitude of these associations, we calculated marginal effects for the ad exposure/policy variables that were significant predictors of support in Model 1, and the ad exposure variables that were significant predictors in Model 5. These analyses held all other variables in the model to their mean values and calculated marginal effects for the predictor variables of interest at the mean and $\pm 1 \mathrm{SD}$. The predicted probability of supporting a ban increased by 1.7 to 2.1 percentage points (depending on whether this was calculated at the mean or $\pm 1 \mathrm{SD}$ from the mean of the predictor) per one-unit increase in overall adult/general-targeted ad exposure (from Model 1). A one-unit increase in exposure corresponds to movement from zero ad exposure to approximately the average level of exposure across markets. Similarly, the predicted probability of supporting a comprehensive ban increased by 1.9 to 2.0 percentage points per one-unit increase in excise taxes and 0.2 percentage points per one-unit increase in the index of youth access to tobacco (Model 1). The predicted probability of supporting a ban increased by 2.0 to 2.2 percentage points per one-unit increase in adult/general-targeted state ads on health consequences of smoking to others, 1.7 to 1.8 percentage points per one-unit increase in ads using anti-industry appeals and 1.5 percentage points per one-unit increase in ads using irrationality/addiction appeals (Model 5).

\section{Logistic regression models predicting support for comprehensive tobacco ad bans}

Model 1 in table 5 shows that market-level volume of exposure to adult/general-state antismoking ads are not associated with support for comprehensive tobacco advertising bans $(B=0.00$, $\mathrm{p}=0.75$ ). Market-level volume of youth-targeted ads predicted increased support for an ad ban $(B=0.02, \mathrm{p}<0.05)$, while market-level volume of truth campaign ads did not. Greater state revenue from tobacco farming predicted significantly lower support for a tobacco ad ban $(B=-1.66, p<0.001)$, while higher cigarette excise taxes $(B=0.11, \mathrm{p}<0.01)$ and greater per capita 
Table 3 Correlation matrix for state antismoking advertisement themes

\begin{tabular}{lllll}
\hline & Efficacy appeal & $\begin{array}{l}\text { Health consequences to } \\
\text { others }\end{array}$ & $\begin{array}{l}\text { Health consequences to } \\
\text { self }\end{array}$ & $\begin{array}{l}\text { Anti-industry } \\
\text { appeal }\end{array}$ \\
\hline Efficacy appeal & 1 & & & $\begin{array}{l}\text { Irrationality/ addiction } \\
\text { appeal }\end{array}$ \\
Health consequences to others & 0.6662 & 1 & 1 & 1 \\
Health consequences to self & 0.7917 & 0.8193 & 0.5756 & 0.4948 \\
\hline Anti-industry appeal & 0.7309 & 0.6524 & 0.5138 & 1 \\
\hline Irrationality/addiction appeal & 0.7359 & 0.5641 & & 1 \\
\hline
\end{tabular}

tobacco control funding $(\mathrm{B}=0.01, \mathrm{p}<0.01)$ predicted greater policy support.

Model 2 shows that exposure to state-sponsored ads emphasising health consequences to self $(B=0.02, \mathrm{p}<0.05)$ predicted greater support for the ban. Models 3 through 6 confirm this finding. Model 6 (the preferred model without multicollinearity issues) shows that the volume of exposure to ads emphasising health consequences to self $(\mathrm{B}=0.03, \mathrm{p}<0.01)$ was an independent and positive predictor of increased support for a tobacco advertising ban.

We again calculated marginal effects for the ad exposure/ policy variables that were significant predictors of support in Model 1 and Model 6. The predicted probability of supporting a ban increased by 0.6 percentage point per one-unit increase in overall youth-targeted ad exposure, decreased by 4.1 to 4.2 percentage points per one-unit increase in the state GDP

Table 4 Logistic regression predicting support for comprehensive indoor smoking bans ( $n=102831)$

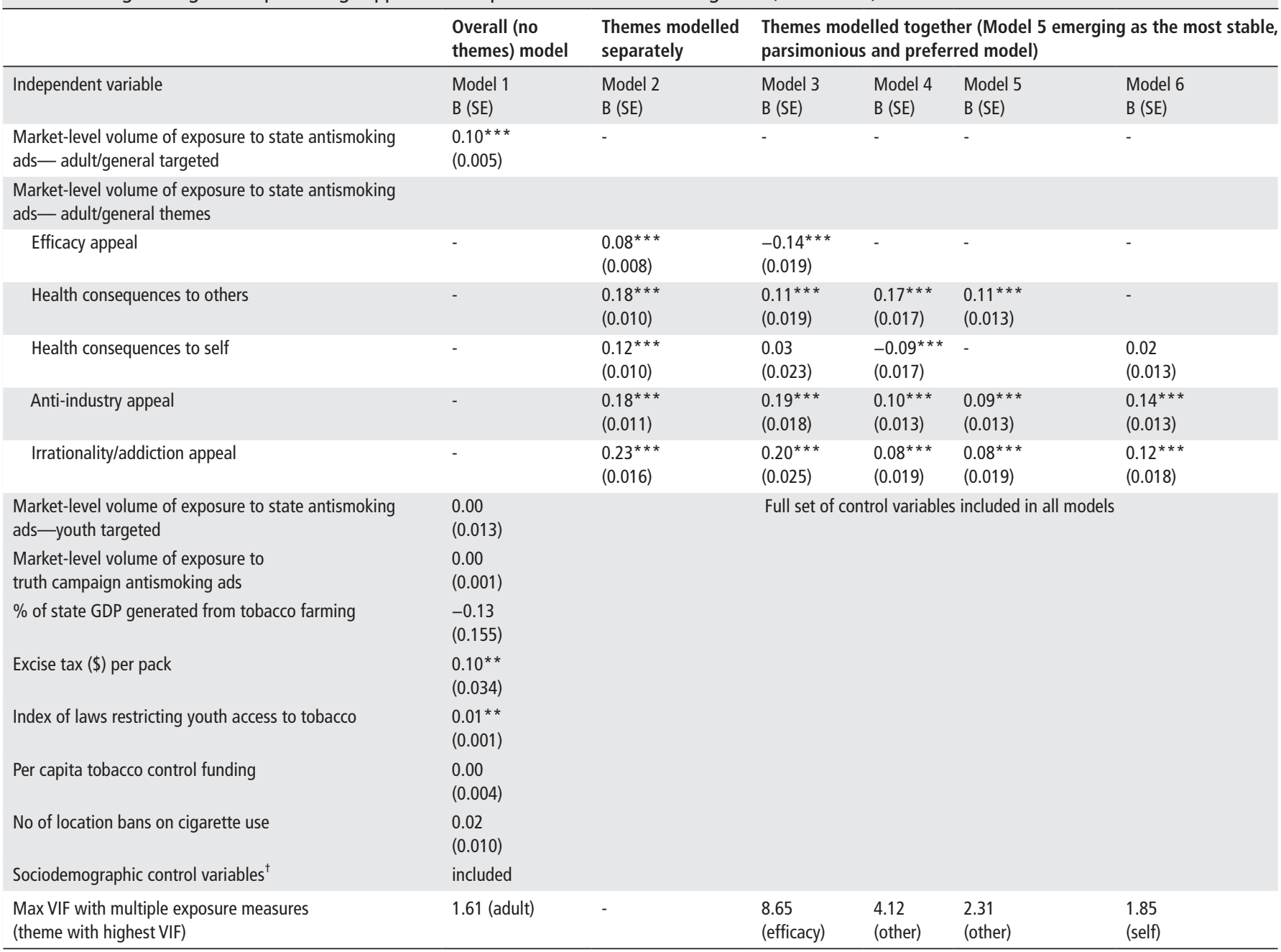

${ }^{*} p<0.05 ;{ }^{* *} p<0.01 ;{ }^{* * *} p<0.001$.

Model 1 presents coefficients for a model that includes the overall volume of adult/general-targeted state antismoking ad exposure; Model 2 presents coefficients for separate models in which each state antismoking ad theme variable was the only state ad exposure variable included; Models 3 through 6 present coefficients from models in which various combinations of state antismoking ad theme exposure measures were entered simultaneously in the same model.

† Demographic control variables include dummy variables for categories of age, gender, race, ethnicity, citizenship status, marital status, educational attainment, household income, employment status, student status, number of children living in the household, smoking status, previous (ever) quit attempts and recent (past year) quit attempts. VIF, variance inflation factor. 
Table 5 Logistic regression predicting support for comprehensive tobacco advertising bans $(n=102831)$

\begin{tabular}{|c|c|c|c|c|c|c|}
\hline \multirow[b]{2}{*}{ Independent variable } & \multirow{2}{*}{$\begin{array}{l}\begin{array}{l}\text { Overall (no } \\
\text { themes) model }\end{array} \\
\text { Model } 1 \\
B(S E)\end{array}$} & \multirow{2}{*}{$\begin{array}{l}\text { Themes modelled } \\
\text { separately } \\
\text { Model } 2 \\
\text { B (SE) }\end{array}$} & \multicolumn{4}{|c|}{$\begin{array}{l}\text { Themes modelled together (Model } 6 \text { emerging as the most } \\
\text { stable, parsimonious and preferred model) }\end{array}$} \\
\hline & & & $\begin{array}{l}\text { Model } 3 \\
\text { B (SE) }\end{array}$ & $\begin{array}{l}\text { Model } 4 \\
\text { B (SE) }\end{array}$ & $\begin{array}{l}\text { Model } 5 \\
\text { B (SE) }\end{array}$ & $\begin{array}{l}\text { Model } 6 \\
\text { B (SE) }\end{array}$ \\
\hline $\begin{array}{l}\text { Market-level volume of exposure to state antismoking } \\
\text { ads- adult/general targeted }\end{array}$ & $\begin{array}{l}0.00 \\
(0.005)\end{array}$ & - & - & - & - & - \\
\hline \multicolumn{7}{|l|}{$\begin{array}{l}\text { Market-level volume of exposure to state antismoking } \\
\text { ads_- adult/general themes }\end{array}$} \\
\hline Efficacy appeal & - & $\begin{array}{l}0.01 \\
(0.007)\end{array}$ & $\begin{array}{l}0.00 \\
(0.017)\end{array}$ & - & - & - \\
\hline Health consequences to others & - & $\begin{array}{l}0.00 \\
(0.009)\end{array}$ & $\begin{array}{l}-0.04^{*} \\
(0.017)\end{array}$ & $\begin{array}{l}-0.04^{*} \\
(0.015)\end{array}$ & $\begin{array}{l}0.00 \\
(0.012)\end{array}$ & - \\
\hline Health consequences to self & - & $\begin{array}{l}0.02^{*} \\
(0.009)\end{array}$ & $\begin{array}{l}0.06^{* *} \\
(0.021)\end{array}$ & $\begin{array}{l}0.06^{* * *} \\
(0.015)\end{array}$ & - & $\begin{array}{l}0.03^{* *} \\
(0.011)\end{array}$ \\
\hline Anti-industry appeal & - & $\begin{array}{l}0.00 \\
(0.010)\end{array}$ & $\begin{array}{l}-0.01 \\
(0.016)\end{array}$ & $\begin{array}{l}-0.01 \\
(0.012)\end{array}$ & $\begin{array}{l}0.00 \\
(0.012)\end{array}$ & $\begin{array}{l}-0.02 \\
(0.012)\end{array}$ \\
\hline Irrationality/ addiction appeal & - & $\begin{array}{l}0.00 \\
(0.015)\end{array}$ & $\begin{array}{l}0.00 \\
(0.022)\end{array}$ & $\begin{array}{l}-0.01 \\
(0.017)\end{array}$ & $\begin{array}{l}0.00 \\
(0.017)\end{array}$ & $\begin{array}{l}-0.01 \\
(0.017)\end{array}$ \\
\hline $\begin{array}{l}\text { Market-level volume of exposure to state antismoking } \\
\text { ads-youth-targeted }\end{array}$ & $\begin{array}{l}0.02^{*} \\
(0.012)\end{array}$ & & \multicolumn{4}{|c|}{ Full set of control variables included in all models } \\
\hline $\begin{array}{l}\text { Market-level volume of exposure to } \\
\text { truth campaign antismoking ads }\end{array}$ & $\begin{array}{l}0.00 \\
(0.001)\end{array}$ & & & & & \\
\hline$\%$ of state GDP - generated from tobacco farming & $\begin{array}{l}-1.66^{* * *} \\
(0.148)\end{array}$ & & & & & \\
\hline Excise tax (\$) per pack & $\begin{array}{l}0.11^{* *} \\
(0.030)\end{array}$ & & & & & \\
\hline Index of laws restricting youth access to tobacco & $\begin{array}{l}0.00 \\
(0.001)\end{array}$ & & & & & \\
\hline Per capita tobacco control funding & $\begin{array}{l}0.01^{* *} \\
(0.003)\end{array}$ & & & & & \\
\hline No of location bans on cigarette use & $\begin{array}{l}0.01 \\
(0.009)\end{array}$ & & & & & \\
\hline Sociodemographic control variablest & included & & & & & \\
\hline $\begin{array}{l}\text { Max VIF in models with multiple exposure measures (theme } \\
\text { with highest VIF) }\end{array}$ & $\begin{array}{l}1.61 \\
\text { (adult) }\end{array}$ & - & $\begin{array}{l}8.65 \\
\text { (efficacy) }\end{array}$ & $\begin{array}{l}4.12 \\
\text { (other) }\end{array}$ & $\begin{array}{l}2.31 \\
\text { (other) }\end{array}$ & $\begin{array}{l}1.85 \\
\text { (self) }\end{array}$ \\
\hline
\end{tabular}

${ }^{*} \mathrm{p}<0.05 ;{ }^{* *} \mathrm{p}<0.01 ;{ }^{* * *} \mathrm{p}<0.001$.

Model 1 presents coefficients for a model that includes the overall volume of adultgeneral-targeted state antismoking ad exposure; Model 2 presents coefficients for separate models in which each state antismoking ad theme variable was the only state ad exposure variable included; Models 3 through 6 present coefficients from models in which various combinations of state antismoking ad theme exposure measures were entered simultaneously in the same model.

tDemographic control variables include dummy variables for categories of age, gender, race, ethnicity, citizenship status, marital status, educational attainment, household income, employment status, student status, number of children living in the household, smoking status, previous (ever) quit attempts and recent (past year) quit attempts. VIF, variance inflation factor.

percentage from tobacco farming, increased by 2.6 percentage points per one-unit increase in excise taxes and increased 0.3 percentage points per one-unit increase in per capita tobacco control funding (from Model 1). The predicted probability of supporting a tobacco ad ban increased by 0.8 percentage points per one-unit increase in the volume of adult/general-targeted ads on the health consequences of smoking to self (Model 6).

\section{DISCUSSION}

This study provides new evidence that large-scale antismoking media campaigns have meaningful secondary impacts on support for tobacco control policy. ${ }^{1-322}$ Market-level exposure to adult/ general audience state antismoking ads was associated with significant increases in support for banning smoking in a wide variety of indoor locations, including bars and restaurants. These effects were driven by (and notably stronger within) ads emphasising three message themes: health consequences of cigarette smoking to others, anti-industry appeals and irrationality/addiction appeals. These theme-specific effects remained significant in models that controlled for multitheme exposure, suggesting that their effects may be additive. Results are consistent with the argument that antismoking campaigns using these themes can denormalise tobacco use by making public smoking seem unacceptable.

Marginal effect analyses suggest that movement from zero ad exposure to the average level of exposure across markets (a one-unit change in exposure) increased the probability of supporting a comprehensive indoor smoking ban by 2 percentage points. This effect was comparable to the impact of a $\$ 1.00$ increase in cigarette excise taxes, one of the tobacco control policies with the strongest evidence for overall impact on tobacco use. ${ }^{26}$ We note here that excise taxes often generate revenue to fund tobacco control efforts, while antismoking media campaigns require substantial levels of funding to reach their audience. The net benefit of excise taxes on broader tobacco control efforts may still be greater. Nevertheless, theme-specific models suggest the potential for additive effects of state campaigns using multiple themes, including health effects on others (about 2 percentage points/one-unit change in exposure), anti-industry appeals (about 1.75 percentage points/one-unit change in exposure) 
and irrationality/addiction appeals (about 1.5 percentage points/ one-unit change in exposure). State campaigns featuring a high volume of ads featuring these primary themes might expect larger increases in support for comprehensive smoking bans.

Evidence of impact was less clear in promoting support for tobacco advertising bans. Market-level exposure to state adult/ general-targeted antismoking ads was not associated with support for this policy, although exposure to youth-targeted ads had a small impact on this outcome (a 0.6 percentage-point increase in policy support/one-unit increase in exposure). Theme-specific models revealed a similarly modest impact of adult/general-targeted ads emphasising health consequences to self $(0.8$ percentage point increase in support/one-unit change in exposure). Both of these effects were much smaller than the apparent impact of being a tobacco producing state, as each 1-percentage increase of state GDP derived from tobacco farming predicted over a 4 percentage-point decrease in support for tobacco ad bans. The impact of a $\$ 1.00$ increase in cigarette excise taxes (an increase in support of 2.6 percentage points) on this outcome also was larger in magnitude. It is possible that public support for tobacco ad bans may be less susceptible to the impact of media messages than policies that aim to protect the health and welfare of others by reducing SHS exposure, although this explanation is speculative.

Contrary to previous work, we found no evidence that having smoking bans already in place increased support for these policies. ${ }^{14-17}$ We suspect that this finding may be explained by limited variation on this outcome during the relatively short duration of the observation period (spanning only 9 months across the three waves), since previous work has consistently found evidence for this effect. We found no evidence that exposure to the youth-targeted, truth antismoking campaign influenced support for tobacco control policy. This finding may stem from the nature of the truth campaign's media placement strategy (targeting $12-17$ year olds, with $18-24$ as a secondary audience, thus not reaching very many adults 18 and older) or the fact that truth was a national campaign and thus had limited variation by media market during this observation period, although we were unable to test these explanations.

\section{Study limitations}

This study used data from 2001 to 2002; the media environment, tobacco control landscape and public opinion climate have changed since this time, so these data may not reflect current levels of policy support. However, the 2001-2002 CPS-TUS and market-level exposure data are uniquely positioned to test our hypotheses about secondary impacts of antismoking campaigns on policy support. First, the CPS-TUS's very large sample (not repeated in the years since) allowed us to detect small but meaningful effects at the population level. Second, DMAs were geographically well defined in 2001-2002 and enabled us to make use of geographic variation in media exposure. This methodological strategy that has become more problematic in recent years as the rise in connective and social media has rendered geographic boundaries less clear.

Our measures of market-level state antismoking ad exposure are linked to individual respondents by their media market of residence; we do not know whether any individual respondent had seen these ads. Previous work does establish that people living in markets with greater ad availability are more likely to remember seeing those ads. ${ }^{26}$ Our ad exposure measures do not account for variations in the size of audience for a particular ad. We assume that state media campaign planners sought to maximise exposure within their state boundaries given resources available to them, and that the volume of these resources is strongly associated with tobacco control funding in a state. Thus, the fact that we accounted for state tobacco control expenditures likely accounts for much of the difference in resources available to generate widespread exposure to antismoking ads appearing within that state.

\section{Conclusion}

Results provide the strongest evidence to date that largescale mass media campaigns targeting adult smokers can have important secondary effects on increasing public support for tobacco control policies, particularly comprehensive indoor smoking bans. Future research should identify the conditions under which mass media campaigns primarily targeting smoking behaviour may influence public support for a variety of other tobacco control policies.

\section{What this paper adds}

- Many scholars suggest that a potential impact of mass media antismoking campaigns may be to increase public willingness to support tobacco control policy, but research has yet to parse out the specific impact of these campaigns in shaping public policy support.

- This study is the first to combine market-level data on state antismoking advertising exposure with a large national sample of US adults between 2001 and 2002 to test whether these campaigns are associated with increased support for tobacco control policy, controlling for demographic factors and other state/national antismoking campaigns, programmes and policies.

- Results provide the strongest evidence to date that largescale mass media campaigns targeting adult smokers can have important secondary effects on increasing public support for tobacco control policy, particularly comprehensive indoor smoking bans.

-We recommend that media campaigns consider emphasising the health consequences of smoking to others, describing negative behaviour of the tobacco industry and discussing the addictive nature of tobacco in efforts to broaden support for comprehensive tobacco control efforts in the USA.

Acknowledgements We thank the directors of the PhADS Lab at Cornell University for the use of their advertising database and the undergraduate research assistants who worked on ad coding for this project: Harlan Pittell, John Cantor, Katherine Strausser, Alice Cope and Julie Spaulding.

Contributors JN conceptualised the study, supervised the statistical analysis, contributed to the interpretation of the data and led the writing of the paper. RJA contributed the time of the research assistants on this project, conceptualised the study, supervised the statistical analysis and helped write the paper. MK conducted the statistical analysis, contributed to interpretation of the data and helped write the paper. CS contributed to the interpretation of the data and helped write the paper.

Funding This paper benefited from the databases generated by two National Institutes of Health grants: 5R01CA094020 An Economic Study of Three decades of Smoking Cessation and 5R01CA113407 Smoking Cessation and Advertising: An Econometric Study.

Competing interests None declared.

Provenance and peer review Not commissioned; externally peer reviewed.

(c) Article author(s) (or their employer(s) unless otherwise stated in the text of the article) 2018. All rights reserved. No commercial use is permitted unless otherwise expressly granted. 


\section{REFERENCES}

1 Wakefield MA, Loken B, Hornik RC. Use of mass media campaigns to change health behaviour. Lancet 2010;376:1261-71.

2 Jeffery RW. Risk behaviors and health: contrasting individual and population perspectives. Am Psychol 1989;44:1194-202.

3 Hornik RC. Alternative models of behavior change. In: Wasserheit J, ed. Research issues in human behavior and sexually transmitted diseases in the AIDS era. Washington, DC: American Society for Microbiology, 1991:201-17.

4 Wlezien C, Soroka SN. The relationship between public opinion and policy. In: Dalton RJ, Klingemann H-D, eds. Oxford handbook of political behavior. Oxford, UK: Oxford, 2007:799-817.

5 Thrasher JF, Huang L, Pérez-Hernández R, et al. Evaluation of a social marketing campaign to support Mexico City's comprehensive smoke-free law. Am J Public Health 2011;101:328-35.

6 Fosson GH, McCallum DM, Conaway MB. Antismoking mass media campaigns and support for smoke-free environments, mobile county, Alabama, 2011-2012. Prev Chronic Dis 2014;11.

7 Quick BL, Bates BR, Romina S. Examining antecedents of clean indoor air policy support: implications for campaigns promoting clean indoor air. Health Commun 2009;24:50-9.

8 Young D, Borland R, Siahpush M, et al; ITC Collaboration. Australian smokers support stronger regulatory controls on tobacco: findings from the ITC Four-Country survey. Aust N Z J Public Health 2007;31:164-9.

9 Lewis S, Sims M, Richardson S, et al. The effectiveness of tobacco control television advertisements in increasing the prevalence of smoke-free homes. BMC Public Health 2015; 15:869.

10 Alday J, Murukutla N, Cedillo C, et al. Smoke-free São Paulo: a campaign evaluation and the case for sustained mass media investment. Salud Publica Mex 2010;52(Suppl 2):S216-25.

11 Hackshaw AK, Law MR, Wald NJ. The accumulated evidence on lung cancer and environmental tobacco smoke. BMJ 1997;315:980-8.

12 Eriksen MP, Cerak RL. The diffusion and impact of clean indoor air laws. Annu Rev Public Health 2008;29:171-85.

13 Hopkins DP, Razi S, Leeks KD, et al; Task Force on Community Preventive Services. Smokefree policies to reduce tobacco use. A systematic review. Am J Prev Med 2010;38(Suppl 2):S275-89.

14 Fong GT, Hyland A, Borland R, et al. Reductions in tobacco smoke pollution and increases in support for smoke-free public places following the implementation of comprehensive smoke-free workplace legislation in the Republic of Ireland: findings from the ITC Ireland/UK Survey. Tob Control 2006;15 Suppl 3(Suppl 3):iii51-8.
15 Fabian LE, Bernat DH, Lenk KM, et al. Smoke-free laws in bars and restaurants: does support among teens and young adults change after a statewide smoke-free law? Public Health Rep 2011;126:669-76.

16 Nagelhout GE, Wolfson T, Zhuang YL, et al. Population support before and after the implementation of smoke-free laws in the United States: trends from 1992-2007. Nicotine Tob Res 2015;17:350-5.

17 Thrasher JF, Pérez-Hernández R, Swayampakala K, et al. Policy support, norms, and secondhand smoke exposure before and after implementation of a comprehensive smoke-free law in Mexico city. Am J Public Health 2010;100:1789-98.

18 Mahood G, Tobacco Industry Denormalization. Telling the truth about the tobacco industry's role in the tobacco epidemic. Canada: Nonsmokers' Rights Association, 2004.

19 Malone RE, Grundy Q, Bero LA. Tobacco industry denormalisation as a tobacco control intervention: a review. Tob Control 2012;21:162-70.

20 Niederdeppe J, Avery R, Byrne S, et al. Variations in state use of antitobacco message themes predict youth smoking prevalence in the USA, 1999-2005. Tob Control 2016;25.

21 Blake KD, Viswanath K, Blendon RJ, et al. The role of tobacco-specific media exposure, knowledge, and smoking status on selected attitudes toward tobacco control. Nicotine Tob Res 2010;12:117-26.

22 Hammond D, Fong GT, Zanna MP, et al. Tobacco denormalization and industry beliefs among smokers from four countries. Am J Prev Med 2006;31:225-32.

23 Allen JA, Davis KC, Kamyab K, et al. Exploring the potential for a mass media campaign to influence support for a ban on tobacco promotion at the point of sale. Health Educ Res 2015;30:87-97.

24 Farrelly MC, Davis KC, Haviland ML, et al. Evidence of a dose-response relationship between 'truth' antismoking ads and youth smoking prevalence. Am J Public Health 2005:95:425-31.

25 Wakefield MA, Durkin S, Spittal MJ, et al. Impact of tobacco control policies and mass media campaigns on monthly adult smoking prevalence. Am J Public Health 2008;98:1443-50.

26 Durkin S, Brennan E, Wakefield M. Mass media campaigns to promote smoking cessation among adults: an integrative review. Tob Control 2012;21:127-38.

27 ImpacTEEN, Roswell Park Cancer Institute, Department of Health Behavior, Division of Cancer prevention and population sciences. https://impacteen.uic.edu/generalarea_ PDFs/chartbook_final071009.pdf (accessed 16 Oct 2016).

28 Alciati MH, Frosh M, Green SB, et al. State laws on youth access to tobacco in the United States: measuring their extensiveness with a new rating system. Tob Control 1998;7:345-52. 